\title{
EU Policies on Preventing and Combating against Violence against Women
}

\author{
Zorica Saltirovska \\ Institute for Security, Defense and Peace, Faculty of Philosophy, Skopje \\ zorica_ind@yahoo.com
}

\begin{abstract}
The European Union is strengthening its efforts in the direction of emphasizing the wide extent and the nature of violence against women. In these efforts, it is supported by its Member-States. They have been using their own initiatives, based on comprehensive data, to participate in the creation of political and practical measures and policies for prevention of and combating this issue. The Council of Europe Convention on Preventing and Combating Violence against Women from 2011 (Istanbul Convention) is the first legally binding regional document which deals comprehensively with various forms of violence against women. The 2012 EU Directive determines minimal standards in the area of justice, protection, and support of victims of crime, whereby special attention is paid to victims of gender-based violence, and victims of sexual violence. Campaigns on the level of memberstates aim at educating men and women on gender-based violence, encouraging victims to report the criminal act, increasing victim protection, raising awareness on the existence of violence against women and on the need of prevention and combating it. The MemberStates ought to reexamine their legislature in the part of violence against women, and synchronize it with the existing instruments of the Union.
\end{abstract}

Keywords: violence, women, gender-based instruments, European Union, EU policies

\section{Introduction}

In spite of the progress in the direction of eliminating gender inequality, some other forms of violence (such as rape, spousal abuse, sexual violence, and workplace and street violence) illustrate the still submissive position of women. Violence against women is increasingly being acknowledged as a form of discrimination and a violation of women's 
fundamental rights. UNIFEM estimates that one in three women worldwide is submitted to some form of gender-based violence (assault, rape, trafficking, abuse, etc) (UNIFEM, 2003:6). The US Center for Disease Control and Prevention reports that each year in the USA 1,500,000 women are being raped and physically assaulted by their intimate partner (Domestic Violence - A National Report, 2005). According to the UK Home Office, domestic violence is the leading cause for female mortality in women aged 19 to 44 . It is exactly this wide dispersion and heavy social and financial consequences that raise the profile of violence against women as a security issue, which is increasingly being included in security policies (Ibid).

The spread of physical and sexual violence against women in the EU countries has called for a comprehensive research of this phenomenon. The results are now used in both national and EU policy-making that introduces and implements new comprehensive measures to combat and adequately respond to the problem of violence against women.

\section{Defining Violence against Women and the EU Approach in Tackling the Problem}

Even though violence against women has always existed, it is not until the last couple of decades that it gains prominence as an issue. The international community is increasingly dealing with gender violence and acknowledges it as a violation of women's human rights. Until recently, violence against women was not considered a criminal act. The situation has changed in the past two decades. Yet it is alarming is that even today women's security does not receive the necessary attention. That is the reason why these problems are often prone to double marginalization - in national security policies, domestic violence is considered a private, domestic affair, whereas in international security it is treated as a national affair of a sovereign state. However, recently many countries have acknowledged the growing violence against women as a violation of human rights and have increased criminalization of its various forms. Furthermore, what is evident is the emergence of political initiatives for changes in legislation.

On an international level, several legal instruments deal with violence against women, the most significant one being the 1992 General Recommendation of the Committee for Elimination of all Forms of Discrimination against Women (CEDAW), which is an amendment of the Convention bearing the same name, which defines gender violence as a form of discrimination which is seriously inhibiting the capacity of women to enjoy the rights and freedoms on an equal basis with men. The UN also founded a working group, 
aiming to provide for a greater systematic support on a national level (A/RES/61/143), and a database on violence against women was subsequently created. The pioneering definition on violence against women was instituted in the 1993 UN Declaration on the Elimination of violence against women (Article 1), stating that violence against women is "any act of gender-based violence that results in, or is likely to result in, physical, sexual or psychological harm or suffering to women, including threats of such acts, coercion or arbitrary deprivation of liberty, whether occurring in public or in private life." This definition was asserted and extended at the Fourth Conference on Women held in Beijing in 1995. Within the Beijing Declaration, an Action Platform was introduced. The definition includes physical, sexual, and psychological violence which occurs within the family lassault, sexual abuse of girls within the family, marital rape, genital mutilation in female children, and other traditional rituals harmful to women, non-marital violence, and violence associated with exploitation), within the wider community (rape, sexual abuse and intimidation at the workplace and in institutions, trafficking in women and forced prostitution), and by the state (violence done or pardoned by the state). In 2006, the UN General Secretary initiated an in-depth study in order to collect data from Member-States on the nature and existence of all forms of violence against women, and national activities to counter these forms of violence.

On a regional level, the Council of Europe has prepared recommendations and resolutions on violence against women, and in 2005 it founded a working group to evaluate national and international measures against this form of violence. The 2006- 2008 campaign combating violence against women aimed at raising public awareness, promoting support and protection of victims, improving data collection, and instigating changes in the legal solutions regarding prevention and combat against this form of violence. In April 2011 the Council of Europe adopted a Convention on Preventing and Combating Violence against Women (Istanbul Convention). It defines violence against women as "violation of human rights and a form of discrimination against women and shall mean all acts of gender-based violence that result in, or are likely to result in, physical, sexual, psychological or economic harm or suffering to women, including threats of such acts, coercion or arbitrary deprivation of liberty, whether occurring in public or in private life". Domestic violence is separately defined as "all acts of physical, sexual, psychological or economic violence that occur within the family or domestic unit or between former or current spouses or partners, whether or not the perpetrator shares or has shared the same residence with the victim". The Istanbul 
Convention binds all parties to criminalize all forms of violence against women, so that these can be recognized, and criminals can be persecuted and punished.

The EU has not adopted a definition on violence against women, and does not dispose of any special legislative to encompass all its forms. The EU invokes existing definitions of the UN and the Council of Europe, while its legal and political approach is based upon focusing on specific forms of violence, such as trafficking in women, and female genital mutilation. On the EU level, there are regulations dealing with certain forms of violence (for instance the Declaration on Gender Equality, which among other things refers to prevention and combating sexual harassment), and on the level of member-states, certain forms of violence against women have been criminalized, though with varying differences regarding acts which have been criminalized, as well as different definitions. In principle, criminal codes of the EU member-states refer to violence, though there are still many impediments as to their efficient and consistent implementation, due to which there is a lack of access to equal compensation and protection of victims. In 2011, the European Commission enacted the Directive establishing minimum standards on the rights, protection, and support for victims of crime, which is especially connected to vulnerable categories and the prevention against secondary victimization due to an inadequate treatment by the criminal justice system. This Directive especially recognizes and singles out victims of gender, sexual, and domestic violence as vulnerable categories, leading to the adequate acknowledgment of their needs. Thus, EU legislative includes the rights of women-victims of violence within the rights of victims of crime in general. Lacking a legal instrument on gender violence, the EU relies on policies and instruments which encompass the issue in an intermediary way, for instance the 2010 Women's Charter; the Mid-term Review of the Strategy for Equality between Women and Men of 2010-2015; the Daphne Program of 2000 which provided for funds for tackling the issue of violence against women in the EU; the Daphne III Program of 2007 on combating violence against children, adolescents, and women, which is a part of the General Program on fundamental rights and justice, etc. In 2011, the European Commission commenced specific action to enact a Strategy on combating violence against women. However, due to lack of firm and consistent data on this issue at EU-level, which could be used in the creation of policies to respond to it, the action was aborted. Instead for the period of 2013-2015 the European Commission undertook specific activities to resolve violence against women in the EU, and placed them within the frame of the Strategy for equality between women and men (a campaign on gender violence, action to end genital mutilation of women, gathering knowledge on the 
gender dimension of human trafficking, exchange of information and best practices among member-states in the combat against violence against women with handicap, etc.) In spite of this, the European NGOs (such as the European Women's Lobby), the European Parliament and especially the Committee on women's rights and gender equality (FEMM), lodged their criticism regarding the lack of specific strategy on actually dealing with the violence, and pointed to the necessity of enacting the specific legislative on EU-level in dealing with this issue.

\section{Scope and Nature of Violence against Women in the EU}

Until 2014 the scope of violence against women in the EU was evaluated on the basis of data gathered from the official statistics of the criminal law within the frame of the EU Strategy for measuring crime, from victimization research, as well as other data gathered by Eurostat and other sources crucial to the Index of Gender Equality (EIGE). The data collection system was not sufficiently developed, and since the data was collected on a national level, it could not be compared properly - the reason being mainly the differences regarding defining violence against women, as well as the improper use of different questionnaires and interviewing methods, different sample structure and size, etc. The data acquired on the spread of violence against women in a country depend on how wide the legal definition for any form of violence is, what is the level of consciousness of women faced with violence and their readiness to acknowledge it as a criminal offence, what is the reporting culture which reflects the women's trust in institutions in charge, what is the level of successful trials against offenders accused of committing such crimes, etc. Consequently, differences between countries regarding this issue can be stemming from these factors and need not reflect the real picture on EU-level.

The research done by the EU Fundamental Rights Agency (FRA) is the pioneering study at EU-level which prodded into the scope and nature of violence against women in all 28 countries, using the same questionnaire, same manner of application, and a randomly chosen sample. The research showed that violence against women in the EU is a widely dispersed criminal act which women do not sufficiently report to the authorities.

Physical violence is one of the forms of violence against women that is most widely spread. Most common forms of acts of violence are shoving, hitting, hair-pulling, grabbing, and slapping. FRA research showed that $31 \%$ of EU women have suffered one or more acts of physical violence after reaching 15 years of age, and $7 \%$ during only one year prior to the research (European Union Agency for Fundamental Rights, 2014). Even 11\% of the former 
category was subject to sexual violence, $2 \%$ of them in the previous year (2011), and $5 \%$ of them had been raped. In both forms of violence, the women's current or former intimate partners, or a third person, were the offenders. In rape cases where the offender is the current partner, the offence had been repeated six or more times, $42 \%$ of the victims being pregnant women. The consequences of the physical and sexual violence are, above all, emotional (fear, rage, states of shock), but also psychological, which are longer-lasting and appear in the form of depression, anxiety, loss of the sense of self-worth, feelings of vulnerability, loss of sleep, inability to maintain concentration, etc. Despite these long-term consequences, only $14 \%$ of the women-victims of physical and sexual violence reported the act of aggression to the police authorities or any organization working to aid victims of violence. One quarter of the victims reported not having reported the act due to shame, and the majority of them failed to notify the authorities due to lack of trust in them (they believe that their claims will be ignored and not be acted upon). Even the women who reported the act are, in great deal, dissatisfied with the assistance they received.

Psychological violence is also widely dispersed. According to FRA research, $43 \%$ of EU women have experienced some form of psychological violence by their current or former partner (humiliation and shaming $-25 \%$, threat of physical violence $-14 \%$, prohibition from exiting the home, removing car keys from their possession or domestic incarceration - $5 \%$ ). Recurrent forms of psychological violence $(7 \%)$ can be recognized by some certain signs, such as decreased independence of the woman or a complete loss of independence in her private or domestic life. Economic violence was reported by $18 \%$ of the women, in the form of obstruction of independent decision-making regarding domestic finances, prohibition against working outside the home, or denying financial means. In part of these cases, the psychological violence was also accompanied by physical or sexual abuse.

FRA survey results show that $18 \%$ of EU women were victims of stalking since they have reached the age of 15 , and $5 \%$ of them had that experience during the previous year. Moreover, $14 \%$ of them received offensive or threatening messages by the stalker, $8 \%$ were stalked to their homes or workplaces, and $3 \%$ of the cases include recurrent destruction of their own property. Virtual stalking (via e-mail, social networks, SMS or internet) specially concerns young women aged 18 to 29 , and $4 \%$ of them have experienced this form of violence. In three thirds (75\%) of these cases, the police never had any information, although interviewees stated that they had experienced the most severe forms of stalking.

The individual concepts of what sexual harassment entails vary, and they are in great deal an expression of social and cultural values, norms, and attitudes regarding 
gender roles and relations. Sexual harassment is defined as a form of gender violence, and thus - sexual abuse. In the FRA research, three forms of sexual harassment were analyzed: physical (unsolicited physical contact, touching, hugging, or kissing) experienced by $29 \%$ of EU women, verbal (offensive comments, inappropriate invitations for dates, offensive or improper comments on physical appearance, intense questioning about private lives) experienced by $24 \%$ of the women, and non-verbal and online harassment (inappropriate and offensive looks, receiving or flashing sexually offensive images or presents, SMSs or emails with sexual content, and inappropriate befriending attempts on social networks) experienced by $11 \%$ of EU women. $45-55 \%$ of these women have faced sexual harassment since the age of 15 , and in the previous year their percentage ranges from 13 to $21 \%$. The majority of these women are aged $18-29$ (38\% in the previous year) and highly-educated women who work at high positions - $75 \%$, and offenders are most often persons previously unknown by the victims (68\%). Only $4 \%$ of the victims of sexual harassment reported the act to the police, and only $1 \%$ of them also sought the council of lawyers or some service offering assistance to victims.

Regarding violence they had experienced prior to the age of $15,12 \%$ of the women reported having experienced some form of sexual abuse, $27 \%$ had experienced physical violence by an adult, and $10 \%$ psychological violence by an adult in the family. Offenders of these acts are mostly parents (in 55\% it is the father, and $45 \%$ the mother), and in cases of sexual violence it is an unknown male - $97 \%$. Furthermore, $73 \%$ of women victims of violence by the current or former partner stated that their children were aware of the violence - which in itself is an act of psychological violence against the children. Almost one third of women who faced sexual violence in after the age of 15 also reported acts of sexual violence in their childhood previously.

In analyzing results from the FRA research, the women's attitudes and their awareness of the violence against them were also taken into consideration. In societies where violence by a partner is a private issue, it is very unlikely that women-victims of such violence will share their experience with members of their wider family and friends, and even less likely that they are going to report it to the authorities. A staggering $78 \%$ consider violence against women to be widely spread in their country, and $39 \%$ of them personally know women who actually fall victims to it. On average, half of the women do not know that in their country, there are laws on domestic violence, and $19 \%$ of them do not know whether there is a service to support women-victims of violence. Only half of the women included in the research have heard about campaigns against violence (and only 
recently), and $87 \%$ of the interviewed women hold that health workers are disinterested when faced with women who come in injured and only routinely ask them questions about possible violence.

\section{New EU Strategic Approach in Combating Violence against Women}

Publishing the FRA research results marked the perfect moment for the EU to start solving the issue of violence against women on the basis of the gathered evidence, and to build a strategy that will deal with the crucial spheres of interest regarding women's experiences with violence. The research results could also be considered an incentive for the member-states to ratify the Council of Europe's Convention on Preventing and Combating violence against women and domestic violence (the Istanbul Convention), as well as an incentive for the EU to join the Convention. They undoubtedly strengthen the need for a consistent implementation of the existent penal measures, most of all through the EU directive on victims of crime. They highlight the importance of EU legislation and the policies concerning violence against women, which have to be put to practice to gain and maximize efficiency (the European Protection Order, and the EU Mutual recognition of protection measures in civil matters). The response measures must encompass multilateral subjects, such as employers, health workers, internet service providers, etc. This is crucially important since many women do not report their experiences with violence to the authorities, which leads to most cases being hidden, which in turn means that offenders are never punished or even opposed. More diverse means need to be found to uncover cases of violence and deal with consequences. Women need to be encouraged to speak out about their experiences, especially in cultures where there is no culture of open discussion on such 'private' matters. In these environments, the rate of violence is always lower (due to the mass number of unreported crimes, the unwillingness to talk about them, and recognize it), and consequently it is not considered a problem in their political circles.

Obviosuly violence against women is a widely spread problem in the EU, and its dispersion calls for a new strategic approach. The scale of the issue greatly supersedes most criminal areas on which EU has placed a political and strategic focus. Women in the EU are not a minority. They comprise one half of the population, and merely by sheer numbers deserve to see this issue in the spotlight. Member-States should at least reexamine their laws and their synchronicity with the Istanbul convention and the directive on victims, both of which have set new standards for response to violence against women. The lawful recognition of violence against women ought to be further strengthened with actions 
to support the victims, satisfying their needs, and punishing offenders. What is especially important to young women who are vulnerable and at risk of becoming victims is prevention, raising awareness on violence against women, and a much needed shift of attitudes regarding this issue. In most cases the offenders in these crimes are men (according to FRA research), so they should be included in campaigns and initiatives against this form of violence, thus encouraging them to respect women and protect their dignity. Violence by an intimate partner must not be treated by countries as a private, but rather as a public problem, and laws must provide the same measure of support as that offered to women who have experienced violence by an unknown person (a person who is not and was not in any intimate relation with the woman victim). In violent relationships, violators must be closely observed to decrease potential of recurrence of the violent act. Therefore, national strategies against domestic violence should not exclude the fact that "the victim and the perpetrator share the same residence" (Article 3 of the Istanbul Convention).

Secondly, the FRA research showed a connection between an overuse of alcohol and increased violence against women by an intimate partner. This element ought to be taken into consideration in national policies and prevention measures, whereby the excess use of alcohol should be treated as a factor leading to violence. Police could contribute to the provision of bullet-proof evidence to this linkage by gathering information on domestic violence under the influence of alcohol in all cases where they are called in to intervene. Moreover, within the national measures for combating violence against women, the problem of overuse of alcohol should be encompassed, and support in this direction should be provided by the alcoholic beverages industry by promoting responsible consumption of alcohol (European Union Agency for Fundamental Rights, 2014).

The rate at which this form of violent crime is reported is also alarmingly low. Only one out of three women facing violence by their partner, and one out of four women facing violence by an unknown offender, were daring enough to report the crime to the police or some other service. The low rate of reporting is a serious problem that the EU needs to address. It is of the utmost importance that women report crimes being done against them, and it is similarly important that social norms be altered in environments that restrict women from sharing their stories. However, another aspect that leaves a lot to be desired is the treatment of the police and the methods it employs when dealing with victims. Many women in the research have stated that they did not dare to report the crime to the police because they either did not believe that the police could do something to assist them, or would not believe them. Women who reported the crime, in most cases, expressed lack of 
satisfaction regarding the work of the police. In EU Member-States, two basic models of police action in cases of violence against women coexist. The first model includes a restraining order (even if the victim and the perpetrator live in the same residence), as a form of police intervention, followed by criminal persecution and a trial. This pilot-model is being used by $11 \mathrm{EU}$ countries. The second model combines detention of the perpetrator with a jury approved restraining order, and is being practiced by at least 5 EU countries (Belgium, France, Ireland, Spain, and Sweden). Despite the fact that both models rely mostly on the police and the judicial system, the support services play a major role in the evaluation of the practical efficacy of the intervention in these incidents. EU countries need to develop other measures to build the trust in the police force, measures which will also serve to prevent and combat violence against women.

When it comes to identification of cases of violence against women, health services i.e. professional medical personnel play a major role. According to the FRA research, they are the most contacted service, which makes them the most reasonable potential in the process of identification of cases of violence, reporting them to the police, providing forensic evidence, and initiating interventions to uncover and solve cases of violence. For this reason, a law on confidentiality needs to be enacted, which will not impede them from reporting the case, if there are reasonable grounds for suspicion. Countries should also be encouraged to provide professional medical personnel that will not only do a routine checkup, but rather be capable and trained to detect cases of violence, and subtly encourage women to talk about their violent experiences.

In comparison with the percentage of women who contacted health services in case of violence, the percentage of those who contacted some professional service for support of victims is quite low (less than 4\%). The reason for this could be found in the fact that in certain countries there are no such services, or there is a lack of information on their existence and roles. Women-victims of violence are reluctant to speak about it because of feelings of shame, guilt, or simply because in their environment there is a culture of placing the blame on the victims. The role of the professional support services is to convince women that they will not react negatively towards them, but will support them, and assist them in dealing with the culture of blame which they will face during the police and judicial questioning, and in the society. The professional services should also work on the detection of hidden cases of violence, and provide the same support to them. A victim's specific needs should be made clear and respected by the employees. Article 93b of the directive on 
victims also envisions investments in associations for support of women-victims of violence, which are supposed to meet the needs of these women.

In the recent years, many EU countries have made significant progress in resolving the issue of violence against women, but that there is a lot more work to be done. The Istanbul convention recommends that EU countries re-examine their existing policies on violence against women and adopt new strategies, or revise the current ones. The efficiency of their policies and measures taken in this direction will be measured according to the rate of reporting cases of this form of violence, and the satisfaction of the victims who have reported it to the authorities in charge. From the aspect of harmonized gathering and exchange of information, it is vitally important that the institutions are in full cooperation, because no action can be efficient if it is being undertaken by merely one institution. The research proved that victims only contact certain institutions, so the cooperation will help in the spreading of information on the cases of violence against women to other institutions, which will undertake any action within their power to shed light and clear these cases. In this way, women will learn to trust these institutions more, and they will feel safer, knowing that each and every measure for their security is being implemented, especially measures assuring that violence is never again directed against them.

\section{Conclusion}

Violence against women is a widely spread, grossly unreported violation of human rights in the EU. The research of FRA is the first and most comprehensive collection of data regarding this form of violence on EU-level. It caused a vivid discussion on the efficacy of the current policy and regulation on violence against women, and have also accentuated the urgent need for a new approach towards this issue, which calls for the development of new policies and a strategy for its resolution on EU and member-states level. Most of all, what is needed is to ensure the acknowledgement of the forms of violence against women as a violation of their fundamental human rights within the criminal justice framework of the EU. The member-states are encouraged to develop new specific action plans to tackle the issue of violence against women (using FRA results) which will encompass all subjects of the civil society which work or could be engaged in working with women-victims of violence. This will provide aid in the efficacy of the practical results and their sustainability. The mechanisms for financing which the Daphne Program is offering could be put to use in further research and the work of the organizations of the civil society dealing with violence against women, especially the services assisting the victims of such crimes. At EU level, the approach 
towards this issue ought to be strengthened, while in this moment it is focused only on victims and their rights. This implies that domestic violence and violence done by an intimate partner should be recognized as a problem demanding state intervention (i.e. a problem of the state), rather than a private or domestic problem. To phrase it differently, the problem of violence against women is a public problem which, due to its wide spread and severe social and financial consequences, should be dealt with as a security issue on EU-level and should also be included in its member-states' security policies as such.

\section{References:}

1. Burgess, A. W., et al., (2010), Victimology - Theories and Applications, Jones and Bartlett Publishers

2. Commission on Domestic Violence, (2010): A nationwide research study on the prevalence of domestic violence against women in Malta and its impact on their employment prospects.

3. Council of Europe, (2011): Convention on preventing and combating violence against women and domestic violence, CETS No. 210, Istanbul.

4. Council of the European Union, (2014): EU Annual Report on Human Rights and Democracy in the World in 2013, 11107/14 COHOM 109 PESC 653 CSOP/PSDC 383 FREMP 127 INF227 JAI 540 RELEX 524, Brussels.

5. Decision No 779/2007/EC of the European Parliament and the Council of 20 June 2007 establishing foe the period 2007-2013 a specific programme to prevent and combat violence against children, young people and women to protect victims and groups at risk (Daphne III Programme) as part of the General Programme Fundamental Rights and Justice, J0 L 173 of 3.07.2007.

6. Directive 2011/36/EC of the European Parliament and of the Council of 5 April 2011 on preventing and combating trafficking in human being and protecting its victims, and replacing Council Framework Decision 2002/629/JHA, 0J 2011 L 101/1.

7. Directive 2012/29/EU of the European Parliament and the Council of 25 October 2012 establishing minimum standards on the rights, support and protection of victims of crime, and replacing Council Framework Decision 2001/220/JHA, 0J 2012 L 315. 
8. Dobash, R. E., et al., (2007), Lethal and Non-lethal Violence against an Intimate Female Partner: Comparing Male Murderers to Non-lethal Abusers, Violence against Women, 13(4).

9. Domestic Violence - A National Report, (2005), http://www.crimereduction.gov.uk/ domesticviolence51

10. EIGE, (2013): Study on international activities in the field of data collection on gender-based violence across the EU, Publication Office of the European Union, Luxembourg.

11. European Commission, (2012): Measuring Crime in the EU - Statistics Action Plan 2011 - 2015, COM (2011) 713, final, Brussels.

12. European Union Agency for Fundamental Rights, (2014): Violence against Women: an EU-wide survey, Publications Office of the European Union, Luxembourg, ISBN 978-92-9239-342-7, doi: 10.2811/62230.

13. LaWall, B., (2010), Domestic Violence Protocol, Pima Country Domestic Violence Taskforce, Tucson.

14. Tavares, C., and Thomas, G., (2010): Crime and criminal justice Statistics in Focus Series 5B/2010, Eurostat: Aebi et al. (2010), European Sourcebook of Crime and Criminal Justice Statistics - 2010, The Hague, Boom juridische uitgevers.

15. UN, CEDAW Committee, (1992): General Recommendation No. 19 Violence against women, adopted at the eleventh session, $A / 47 / 38$.

16. UNIFEM, (2003), Not a Minute More: Ending Violence against Women, New York

17. UNODC, (2010), Gender in the Criminal Justice System Assessment Tool, United Nations, New York.

18. WHO, (2005): WHO Multi-country Study on women's health and domestic violence against women, Geneva, WHO. 